\title{
Avaliação dos Fatores que Influem nas Medidas Lineares do Cavalo Pantaneiro
}

\author{
Márcia Gabriel Miserani ${ }^{1}$, Concepta McManus ${ }^{2}$, Sandra Aparecida Santos ${ }^{3}$, Joaquim Augusto da Silva ${ }^{4}$, \\ Arthur da Silva Mariante ${ }^{5}$, Urbano Gomes Pinto de Abreu ${ }^{6}$
}

\begin{abstract}
RESUMO - O objetivo deste trabalho foi avaliar os efeitos de sexo, sub-região, idade de registro e ano de nascimento sobre 15 medidas lineares (altura da cernelha, altura do dorso, altura da garupa, altura dos costados, comprimento da cabeça, comprimento do pescoço, comprimento dorso-lombar, comprimento da garupa, comprimento da espádua, comprimento do corpo, largura da cabeça, largura do peito, largura da anca, perímetro do tórax e perímetro da canela) do Cavalo Pantaneiro. Foram analisados dados de 1.214 animais coletados pela Associação Brasileira de Criadores do Cavalo Pantaneiro - ABCCP, no período de 1972 a 1991, usando os procedimentos PRINCOMP, CORR e GLM do SAS e o programa GENES. O sexo, a idade do animal na hora do registro, sub-regiões e ano de registro foram fontes significativas de variação. Os animais, em geral, apresentaram tamanhos pequeno a médio, sendo que os animais da sub-região de Corumbá foram, geralmente, maiores que os de outras sub-regiões. A melhor época para avaliar as medidas morfométricas dos animais seria a partir dos 4 anos de idade. As correlações entre altura de cernelha, altura do dorso e altura da garupa foram altas e positivas, porém entre as outras medidas lineares, médias e baixas. No método de agrupamento, também houve variação de tipo de animais.
\end{abstract}

Palavras-chave: ano, idade, equinos, Pantanal, sub-região

\section{Evaluation of the Factors which Influence Linear Measurements of the Pantaneiro Horse}

\begin{abstract}
The objective of this work was to evaluate the effects of sex, sub-region, age at registration and year of registration, on 15 linear measures (withers height, back height, croup height, midback height, head length, neck length, back-loins length, croup length, shoulder bone length, body length, head width, chest width, hip width, thorax perimeter and shin bone perimeter) of the Pantaneiro horse. Data from 1214 animals were used, registered in the Brazilian Pantaneiro Horse Association, from 1972 to 1991 , and analyzed using GLM, PRINCOMP and CORR procedures of SAS and grouping procedures of the GENES program. The sex, animal age at registration, sub-region and year of registration were significant sources of variation for most of the characteristics studied. The animals of the Corumba region were in general larger than the animals from the other regions. Morphological measures should be taken on the animals from 4 years of age. Correlations between hip height, back height and shoulder height were high and positive, but between other measures were medium to low. Using the grouping method there are several grouping of animals by type which need to be further investigated.
\end{abstract}

Key Words: age, year, horse, Pantanal, sub-region

\section{Introdução}

O cavalo Pantaneiro tornou-se um fator de importância econômica e social no Pantanal MatoGrossense. Ele é essencial no manejo com o gado e capaz de suportar marchas por períodos prolongados em áreas alagadas que ocorrem na estação chuvosa, que vai de outubro a abril.

O melhoramento animal implica em manipulação genética, com o envolvimento de vários aspectos dos organismos vivos. A alteração da morfologia, isto é, do tamanho e/ou forma do animal, constituiu uma das áreas de interesse do melhoramento genético dos animais domésticos. A existência de associações entre a forma e a função dos eqüinos implica na necessidade de se realizarem avaliações morfométricas adequadas destes animais (Barbosa, 1993). A seleção zootécnica deve ser feita preferencialmente dentro da raça com o objetivo de corrigir os defeitos que possam prejudicar e/ou impedir a sua utilização (Santos, 1993), mas no início do século XIX ou talvez no final do século passado, houve cruzamentos com eqüinos das raças Árabe, Anglo Árabe e Puro Sangue Inglês com o Pantaneiro, buscando

\footnotetext{
${ }^{1}$ Mestrando, Fac. Agron. e Méd. Veter. (FAV), Universidade de Brasília, 70910-900. E.mail: miseranim@ig.com.br

${ }^{2}$ Professora, FAV, Universidade de Brasília, 70910-900. E.mail: concepta@unb.br

${ }^{3}$ Pesquisadora, Embrapa Pantanal. E.mail: sasantos@cpap.embrapa.br

4 Técnico da EMPAER - MT, Rua: Joaquim Murtinho s/n Poconé, MT.

${ }^{5}$ Embrapa Recursos Genéticos e Biotecnologia. E.mail: mariante@cenargen.embrapa.br

${ }^{6}$ Pesquisador da Embrapa Pantanal. E.mail: urbano@cpap.embrapa.br
} 
melhorar a conformação e elevar o seu porte sem nenhum critério zootécnico. Além disso, observou-se que os melhores animais da raça Pantaneira eram castrados e utilizados nos trabalhos das fazendas, deixando a paternidade para os animais inferiores (Beck, 1989).

Em 1972, foi criada a Associação Brasileira de Criadores do Cavalo Pantaneiro (ABCCP), que iniciou a conservação deste ecótipo enquanto na década de 80, outras instituições governamentais iniciaram estudos sobre a raça. A EMBRAPA/Pantanal implantou, em 1988, um núcleo de criação de cavalos Pantaneiros na fazenda Nhumirim, sub-região da Nhecolândia, Corumbá - MS e neste núcleo são realizados estudos relacionados aos aspectos nutricionais, reprodutivos, sanitários e de desempenho. Paralelamente, a EMBRAPA/Pantanal realiza trabalhos de caracterização do sistema de criação no Pantanal, estudos sobre a origem e caracterização genética da raça Pantaneira (Santos, 1993).

Sabendo-se da necessidade de levar ao conhecimento dos técnicos e criadores a influência de diversos fatores sobre as medidas lineares dos animais, este trabalho tem como objetivo identificar e quantificar os efeitos ambientais que interferem nestas medidas.

\section{Material e Métodos}

Os dados de garanhões e éguas registrados durante o período de 1972 a 1991, num total de 1214 animais, foram coletados diretamente dos livros de registro definitivo da Associação Brasileira de Criadores do Cavalo Pantaneiro (ABCCP), com sede em Poconé, MT, referentes a informações de origem e conformação. Os animais registrados foram provenientes de 20 sub-regiões: Poconé, Cáceres, Cuiabá, Juscimeira, Maracaju, Rio Verde, Rio Branco, Rosário do Oeste, Santo Antônio do Leverger, Barão de Melgaço, Daimantina, C. Grande, Araputanga e Corumbá. Foram estudadas as seguintes características: altura de cernelha, altura de dorso, altura de garupa, altura de costado, comprimento da cabeça, comprimento do pescoço, comprimento dorso-lombar, comprimento da garupa, comprimento do corpo, comprimento de espádua, largura de cabeça, largura de peito, largura de anca, perímetro do tórax e perímetro da canela. As definições e localizações anatômicas das medidas lineares são subscritas de acordo com Ribeiro (1988) e Costa et al. (1998):
Altura da cernelha: altura tomada no ponto mais alto da região interescapular (espaço definido pelo processo espinhoso de $\mathrm{T}_{5}-\mathrm{T}_{6}$ ) até o solo.

Altura na garupa: altura tomada no ponto mais alto da garupa; espaço definido pelo processo espinhoso de $\mathrm{T}_{5}-\mathrm{T}_{6}$ (sobre a tuberosidade sacral do íleo), até o solo.

Altura do dorso: é a distância vertical tomada do dorso ao solo. Esta medida, comparada com a altura na cernelha e da garupa, mostra o grau de enselamento da referida região.

Altura da cernelha ao esterno, do tórax ou dos costados: é a vertical que desce pelo cilhadouro, partindo da cernelha ao esterno.

Comprimento da cabeça: distância entre a extremidade proximal da cabeça, que coincide com a crista da nuca, e a parte medial ou central da arcada incisiva inferior.

Comprimento do pescoço: distância entre a parte cranial do arco dorsal do atlas e o terço médio das bordas craniais do músculo supraespinhal e escápula.

Comprimento do dorso-lombar: distância entre o espaço interespinhal das extremidades dos processos espinhosos de $\mathrm{T}_{8}$ e $\mathrm{T}_{9}$ e a parte cranial do espaço entre as tuberosidades sacrais.

Comprimento da garupa: distância entre as partes cranial da tuberosidade ilíaca e a caudal da tuberosidade isquiática.

Comprimento da espádua: é a distância da ponta superior da espádua, na altura da cernelha, aos encontros.

Comprimento do corpo: distância entre a parte cranial do tubérculo maior do úmero e a tuberosidade isquiática.

Largura da cabeça: distância compreendida entre a parte livre da borda supra-orbital direita até a borda esquerda.

Largura do peito: distância entre as partes craniais do tubérculo maior dos úmeros direito e esquerdo.

Largura de anca: é a distância compreendida entre as pontas das ancas.

Perímetro do tórax: é a circunferência externa da cavidade torácica, tomada com a fita métrica ao nível do cilhadouro.

Perímetro da canela: é a medida de contorno desta região.

Foram estimados os efeitos dos fatores sexo, subregião, idade de registro e ano de nascimento dos animais sobre as medidas lineares. 
O modelo utilizado na avaliação dos efeitos citados acima sobre as medidas lineares foi o seguinte:

$$
\mathrm{Y}_{\mathrm{ijklm}}=\mathrm{m}+\mathrm{O}_{\mathrm{i}}+\mathrm{R}_{\mathrm{j}}+\mathrm{T}_{\mathrm{k}}+\mathrm{A}_{\mathrm{l}}+\mathrm{e}_{\mathrm{ijklm}}
$$

em que: $\mathrm{Y}_{\mathrm{ijklm}}=$ variável dependente; uma das 15 medidas lineares; $\mathrm{m}=$ média geral, associada à variável dependente; $\mathrm{O}_{\mathrm{i}}=$ efeito fixo do $\mathrm{i}$ ésimo sexo do animal ( $i=$ Macho ou Fêmea); $R_{j}=$ efeito fixo da $\mathrm{j}$ ésimo sub-região $(\mathrm{j}=1, \ldots, 20) ; \mathrm{T}_{\mathrm{k}}=$ efeito fixo da $\mathrm{k}$ ésimo idade ao registro $(\mathrm{k}=2, \ldots, 9) ; \mathrm{A}_{1}=$ efeito fixo do 1 ésimo ano de nascimento $(1=1963, \ldots, 1988)$; $\mathrm{e}_{\mathrm{ijklm}}=$ resíduo aleatório associado a cada observação.

Os dados foram analisados usando o programa estatístico SAS (1999) usando os procedimentos GLM (modelo linear geral) e CORR (correlações). A técnica de análise dos componentes principais consiste em transformar o conjunto de $v$ variáveis em um novo conjunto, que é função linear das funções originais e independentes entre si. Os componentes principais são usados para reduzir o número de variáveis e detectar a relação entre eles. A técnica baseia-se na maximização do espaço original de variação e o alvo da rotação é maximizar a variação do novo variável (componente), enquanto minimiza a variância em volta da nova variável (Joliffe, 1986). Entre todos os componentes, o primeiro apresenta a maior variância, o segundo componente tem a segunda maior variância e assim sucessivamente. Os componentes foram analisados usando o procedimento PRINCOMP. Foram feitos agrupamentos pelo método de Tocher no programa Genes (Cruz, 1997) usando diferentes sub-grupos: por sub-região e por ano de registro, com as seguintes medidas:

1) com todas as 15 medidas juntas.

2) com partes do corpo do animal: cabeça (comprimento do pescoço, comprimento da cabeça, largura da cabeça), posterior (altura da garupa, altura do costado, comprimento da garupa, largura da anca), anterior (altura da cernelha, comprimento da espádua, largura do peito) e central (altura do dorso, comprimento dorso-lombar, perímetro do tórax).

3) com as alturas (altura da cernelha, altura do dorso, altura da garupa, altura do costado), comprimentos (comprimento da cabeça, comprimento do pescoço, comprimento dorso-lombar, comprimento da garupa, comprimento da espádua, comprimento do corpo) e larguras (largura da cabeça, largura do peito, largura da anca).

R. Bras. Zootec., v.31, n.1, p.335-341, 2002 (suplemento)

\section{Resultados e Discussão}

$\mathrm{Na}$ análise dos resultados, observou-se que os efeitos do sexo, da sub-região, da idade do registro e do ano de nascimento foram causas importantes de variações em todas as medidas lineares (Tabela 1). Os coeficientes de variação $(\mathrm{CV})$ da maioria das características analisadas foram menores que $10 \%$, os maiores sendo para as características de comprimento dorso-lombar de 14,58, seguido pela largura da cabeça, de 9,47 e largura do peito, de 8,61. Esta maior variabilidade pode ser decorrente das tomadas de medidas por diferentes pessoas. Mawdsley et al. (1996) acharam CVs maiores que $10 \%$ na maior parte das características estudadas no Puro Sangue Inglês, enquanto Sabeva (1998) observou baixos CVs nas medidas lineares com cavalos oriundos de cruzamentos de Puro Sangue Inglês com Cavalo de Monta do Oeste da Bulgária.

O sexo teve efeito significativo $(\mathrm{P}<0,01)$ em todas as características estudas, exceto altura do costado, comprimento do pescoço e garupa, e largura da cabeça e da anca. O sexo dos animais influenciou a altura da cernelha. Os machos apresentaram altura de cernelha de $141,67 \mathrm{~cm}$ e as fêmeas de $136,87 \mathrm{~cm}$, o que foi semelhante a apresentada por Domingues (1957) e Santos (1993). As éguas estudadas apresentam a altura da cernelha relativamente mais baixa do que a altura da garupa. De acordo com Ribeiro (1988) a altura da cernelha deve ser a mesma da garupa para uma boa proporção do animal. O sexo dos animais também influenciou na altura da garupa, com os machos apresentando valores de $141,81 \mathrm{~cm}$ e as fêmeas de 137,87 cm. Em outros estudos, o sexo não foi um fator significativo nas características lineares do cavalo (Cooper et al., 1999) ou em só alguns (Jakubec et al., 1999). O fato de algumas características não terem diferenças significativas entre machos e fêmeas pode ser atribuído ao maior rigor na apresentação e registro definitivo dos machos (Costa et al., 1998).

$\mathrm{O}$ ano de registro somente não afetou a altura da cernelha e altura do dorso, talvez seja por causa da qualidade das pastagens, do estado nutricional dos animais, do manejo em geral e das variações nas mensurações feitas por diferentes técnicos de registro. Isto está de acordo com a literatura para outras raças brasileiras (Zamborlini et al., 1996; Costa et al., 1998). 
Tabela 1 - Resumo da análise de variância para medidas lineares do cavalo Pantaneiro Table 1 - Analysis summary for linear measurements on the Pantaneiro horse

\begin{tabular}{|c|c|c|c|c|c|c|c|c|c|c|c|c|c|c|c|}
\hline & $\mathrm{V} 1$ & $\mathrm{~V} 2$ & $\mathrm{~V} 3$ & V4 & V5 & V6 & $\mathrm{V7}$ & V8 & V9 & V10 & V11 & V12 & V13 & V14 & $\mathrm{V} 15$ \\
\hline $\begin{array}{l}\text { Sexo } \\
\text { Sex }\end{array}$ & $* *$ & $* *$ & $* *$ & $\mathrm{~ns}$ & $* *$ & $\mathrm{~ns}$ & $* *$ & Ns & $* *$ & $* *$ & $\mathrm{~ns}$ & $* *$ & $\mathrm{~ns}$ & $* *$ & $* *$ \\
\hline $\begin{array}{l}\text { Sub-região } \\
\text { Subregion }\end{array}$ & $* *$ & $* *$ & $* *$ & $* *$ & $* *$ & $* *$ & $* *$ & $* *$ & $* *$ & $\mathrm{~ns}$ & $* *$ & $* *$ & $* *$ & $* *$ & $\mathrm{~ns}$ \\
\hline $\begin{array}{l}\text { Idade } \\
\text { Age }\end{array}$ & $\mathrm{ns}$ & $\mathrm{ns}$ & $\mathrm{ns}$ & $* *$ & $\mathrm{~ns}$ & $* *$ & $* *$ & Ns & $* *$ & $* *$ & $* *$ & $* *$ & $* *$ & $\mathrm{~ns}$ & $\mathrm{~ns}$ \\
\hline $\begin{array}{l}\text { Ano } \\
\text { Year }\end{array}$ & $\mathrm{ns}$ & $\mathrm{ns}$ & $* *$ & $* *$ & $* *$ & $* *$ & $* *$ & $* *$ & $* *$ & $* *$ & $* *$ & $* *$ & $* *$ & $* *$ & $* *$ \\
\hline $\begin{array}{l}\text { Média }(\mathrm{cm}) \\
\text { Mean }(\mathrm{cm})\end{array}$ & 137,65 & 135,19 & 138,51 & 58,42 & 53,7 & 57,3 & 44,47 & 44,92 & 46,3 & 141,89 & 20,43 & 32,01 & 43,52 & 160,61 & 17,59 \\
\hline $\begin{array}{l}\mathrm{CV}(\%) \\
\mathrm{DP} \\
S D\end{array}$ & $\begin{array}{l}1,44 \\
1,98\end{array}$ & $\begin{array}{l}1,84 \\
2,48\end{array}$ & $\begin{array}{l}1,67 \\
2,31\end{array}$ & $\begin{array}{l}5,32 \\
3,107\end{array}$ & $\begin{array}{l}4,35 \\
2,33\end{array}$ & $\begin{array}{l}5,96 \\
3,41\end{array}$ & $\begin{array}{r}14,58 \\
6,48\end{array}$ & $\begin{array}{l}5,6 \\
2,51\end{array}$ & $\begin{array}{l}6,48 \\
3,00\end{array}$ & $\begin{array}{r}7,06 \\
10,01\end{array}$ & $\begin{array}{l}9,47 \\
1,93\end{array}$ & $\begin{array}{l}8,61 \\
2,75\end{array}$ & $\begin{array}{l}6,27 \\
2,72\end{array}$ & $\begin{array}{l}3,17 \\
5,09\end{array}$ & $\begin{array}{l}4,9 \\
0,86\end{array}$ \\
\hline
\end{tabular}

A idade de registro, em geral, não afetou significativamente $(\mathrm{P}<0,01)$ as alturas, exceto do costado, e perímetros, bem como comprimento da cabeça e da garupa. A não influência da idade de registro sobre a altura da cernelha, provavelmente, é devido à exigência pela $\mathrm{ABCCP}$ de altura mínima para registro, de $135 \mathrm{~cm}$ para fêmeas e $140 \mathrm{~cm}$ para machos. Os animais com idades de dois e três anos tiveram médias das medidas lineares menores que as dos outros animais mais velhos, de 4 a 9 anos, para altura do costado, comprimento do pescoço, do dorso-lombar, corpo e espádua, bem como as larguras de cabeça, peito e anca. Isto pode acontecer porque os animais mais jovens ainda estão em fase de crescimento. Reed \& Dunn (1977), estudando cavalos Árabes, observaram que os machos crescem em altura até cinco anos de idade, enquanto as fêmeas até quatro anos de idade. Observações semelhantes foram encontradas por Santos et al. (1999) com cavalos Pantaneiros. Portanto, a idade ideal para avaliar as medidas morfométricas dos cavalos Pantaneiros seria a partir dos 4 anos de idade, de acordo com os resultados das análises.

De acordo com Ribeiro (1988), o cavalo é grande quando ultrapassa 1,60 m; médio, entre 1,50 e 1,60 m; pequeno, entre 1,30 e 1,50 m; e com menos de 1,30 m são considerados pôneis ou piquiras. O cavalo Pantaneiro pode ser considerado de tamanho pequeno.

R. Bras. Zootec., v.31, n.1, p.335-341, 2002 (suplemento)
Das 15 características estudadas só não houve diferenças $(\mathrm{P}>0,05)$ entre as sub-regiões, para comprimento do corpo e perímetro da canela. Houve variação morfológica do cavalo Pantaneiro, de acordo com à sub-região de origem. Os primeiros cavalos que chegaram a região do Pantanal aclimataram-se e multiplicaram-se facilmente e de acordo com o ambiente característico de cada sub-região apareceram diferentes fenótipos (Santos et al., 1992). Somente em 1972, com a criação da ABCCP, foi possível a junção destes fenótipos para a formação da raça Pantaneira. Tal fato explica a variação existente entre as sub-regiões. Os animais da sub-região de Corumbá foram os que apresentaram estatura física maior, provavelmente devido à estatura dos cavalos de origem, como também à presença de condições ambientais mais apropriadas. A diferença em tamanho entre os animais da região de Corumbá e as outras regiões foi de 5 a $20 \%$ para as características examinadas. Houve aproximação nas médias da altura da cernelha e garupa, tanto para os animais de Corumbá como para as demais sub-regiões.

Algumas outras regiões mostram diferenças significativas relativas a algumas características. A média do comprimento do pescoço da sub-região de Cáceres, de $60,93 \mathrm{~cm}$, foi elevada em relação à média das outras sub-regiões, de $57,30 \mathrm{~cm}$, bem como a média da altura do costado da sub-região de Araputanga, de $64,00 \mathrm{~cm}$, em relação à média das 
outras sub-regiões, de $58,42 \mathrm{~cm}$. Isto pode representar uma preferência por tipo de animal pelos criadores da região.

De acordo com Correa Filho (1973) e Domingues (1975), o cavalo pantaneiro é, provavelmente, oriundo de eqüino de origem lusitana (Céltico Lusitano, Barbo e Andaluz), da raça Árabe e Crioulo Argentino. Cothran et al. (1998) demonstraram relações genéticas do cavalo Pantaneiro com os eqüinos da Península Ibérica (Andaluz e Lusitana) e com as demais raças brasileiras, especialmente a Mangalarga.

De acordo com a Tabela 2, as correlações entre as alturas da cernelha, dorso e garupa foram altas e positivas, de 0,79 a 0,86 , mas com as outras características foram médias a baixas. As correlações entre os vários comprimentos foram, em geral, médias a baixas com valores mais altos entre comprimento da garupa e comprimento da espádua, de 0,56 . As correlações das características com comprimento dorso-lombar foram, em geral, baixas ou negativas. A correlação entre comprimento do pescoço e do dorso lombar foi de $-0,30$, exceto perímetro de tórax, que foi 0,36 . A mais alta correlação entre as larguras foi de 0,55 , entre largura do peito e largura da anca. As correlações entre os comprimentos, larguras, alturas e perímetros foram também médias a baixas. Estes resultados estão de acordo com os obtidos por Vassiley \& Sabeva (1996) avaliando o Cavalo de Monta do Oeste da Bulgária. As correlações estimadas aqui mostram que, selecionando o cavalo Pantaneiro para uma característica, não necessariamente terá uma resposta desejada nas outras características desejáveis.

Para explicar melhor as (co)variações entre as várias características foi realizada um análise de componentes principais e agrupamento. Os primeiros autovetores são representados graficamente na Figura 1. Nota-se, no primeiro componente (autovetor 1), que são animais altos e compridos, pois a altura da cernelha, a altura da garupa e o comprimento do corpo apresentam-se maiores. Em geral, um animal maior para uma característica é maior para todas. O segundo componente (autovetor 2) descreve animais mais altos, dorso comprido, circunferência de peito grande, com animais de pescoço curto, cabeça fina, anca curta, costado baixo, canela fina, espádua curta. Os dois primeiros componentes principais explicam $46 \%$ da variação das 15 características estudadas.

Os métodos de agrupamento hierárquico, de otimização ou gráfico, permitem o estabelecimento de grupos, de tal forma que exista homogeneidade dentro do grupo e heterogeneidade entre grupos. Alternativamente, as técnicas de análise de agrupamento têm por objetivo, ainda, dividir um grupo original de observações em vários grupos, segundo algum critério de similaridade ou dissimilaridade. O método de Tocher é uma técnica de otimização, que agrupa os indivíduos mantendo-se o critério de que as distâncias intragrupos são sempre menores do que as intergrupos (Cruz, 1991).

Tabela 2 - Correlações entre as medidas lineares do cavalo Pantaneiro

Table 2 - Correlations between linear measurements on Pantaneiro horse

\begin{tabular}{|c|c|c|c|c|c|c|c|c|c|c|c|c|c|c|}
\hline & $\mathrm{V} 1$ & $\mathrm{~V} 2$ & V3 & V4 & V5 & V6 & $\mathrm{V} 7$ & V8 & V9 & V10 & V11 & V12 & V13 & V14 \\
\hline $\mathrm{V} 2$ & 0,80 & & & & & & & & & & & & & \\
\hline $\mathrm{V} 3$ & 0,86 & 0,79 & & & & & & & & & & & & \\
\hline V4 & 0,25 & 0,29 & 0,28 & & & & & & & & & & & \\
\hline V5 & 0,26 & 0,22 & 0,29 & 0,34 & & & & & & & & & & \\
\hline V6 & 0,12 & 0,15 & 0,15 & 0,34 & 0,24 & & & & & & & & & \\
\hline $\mathrm{V7}$ & 0,22 & 0,11 & 0,19 & $-0,10$ & 0,07 & $-0,30$ & & & & & & & & \\
\hline V8 & 0,23 & 0,18 & 0,23 & 0,39 & 0,34 & 0,35 & $-0,10$ & & & & & & & \\
\hline V9 & 0,26 & 0,14 & 0,26 & 0,40 & 0,34 & 0,31 & $-0,00$ & 0,56 & & & & & & \\
\hline V10 & 0,23 & 0,16 & 0,22 & 0,17 & 0,14 & 0,21 & $-0,00$ & 0,20 & 0,19 & & & & & \\
\hline V11 & 0,13 & 0,13 & 0,11 & 0,34 & 0,27 & 0,34 & $-0,30$ & 0,34 & 0,28 & 0,14 & & & & \\
\hline V12 & 0,35 & 0,33 & 0,36 & 0,41 & 0,34 & 0,21 & 0,01 & 0,36 & 0,27 & 0,14 & 0,38 & & & \\
\hline V13 & 0,24 & 0,25 & 0,28 & 0,41 & 0,39 & 0,25 & $-0,10$ & 0,47 & 0,38 & 0,16 & 0,34 & 0,55 & & \\
\hline V14 & 0,35 & 0,27 & 0,38 & 0,24 & 0,19 & 0,01 & 0,36 & 0,26 & 0,29 & 0,08 & $-0,10$ & 0,27 & 0,23 & \\
\hline V15 & 0,26 & 0,14 & 0,23 & 0,23 & 0,24 & 0,09 & $-0,10$ & 0,34 & 0,37 & 0,14 & 0,23 & 0,31 & 0,30 & 0,21 \\
\hline
\end{tabular}

V1 = altura da cernelha; V2 = altura do dorso; V3 = altura da garupa; V4 = altura do costado; V5 = comprimento da cabeça; V6 = comprimento do pescoço; V7 = comprimento dorso-lombar; V8 = comprimento da garupa ; V9 = comprimento de espádua; $\mathrm{V} 10=$ comprimento do corpo; $\mathrm{V} 11$ = largura da cabeça; $\mathrm{V} 12$ = largura do peito; V13 = largura da anca; V14 = perímetro do tórax; $\mathrm{V} 15$ = perímetro da canela.

V1 = withers height; $V 2=$ back height; $V 3=$ croup height; $V 4=$ midback height; $V 5=$ head length; 6 = neck length; V7 = back-loin length; V8 = croup length ; V9 = shoulder bone length, ; V10 = body length; V11 = head width; V12 = chest width; V13 = hip width; V14 = thorax perimeter; V15 = shin bone perimeter 


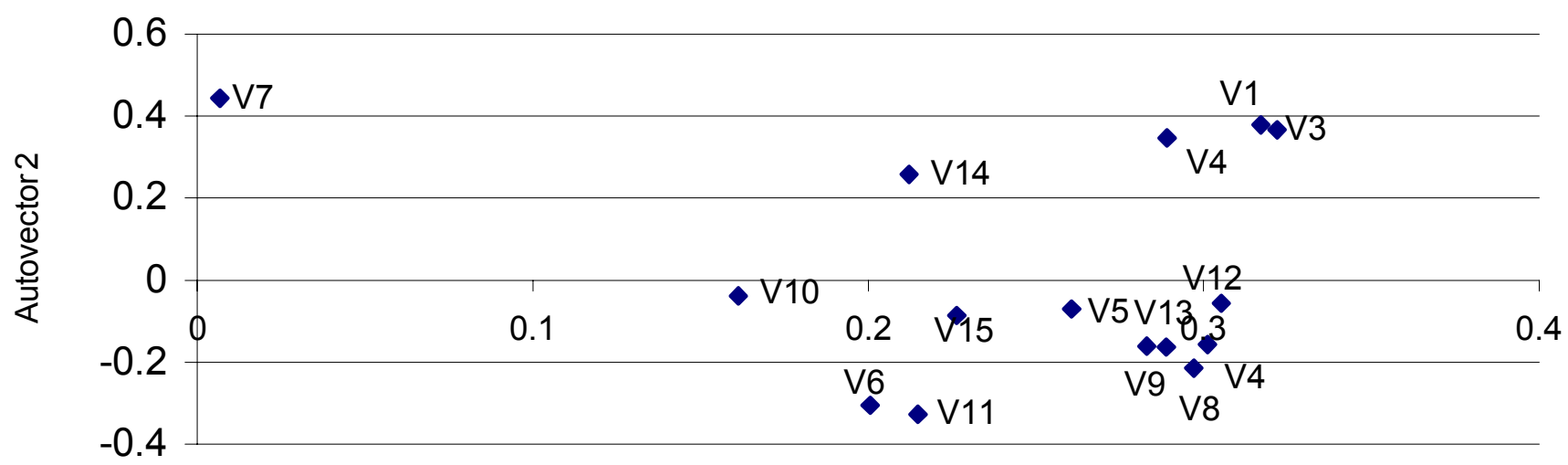

Autovector 1

Figura 1 - Componentes principais para medidas de tamanho no Cavalo Pantaneiro.

Figure 1 - Principal components for size measures of Pantaneiro Horse.

V1 = altura da cernelha; V2 = altura do dorso; V3 = altura da garupa; V4 = altura do costado; V5 = comprimento da cabeça; V6 = comprimento do pescoço; V7 = comprimento dorso-lombar; V8 = comprimento da garupa ; V9 = comprimento de espádua; V10 = comprimento do corpo; V11 = largura da cabeça; V12 = largura do peito; V13 = largura da anca; V14 = perímetro do tórax; $\mathrm{V} 15$ = perímetro da canela.

V1 = withers height; V2 = back height; V3 = croup height; V4 = midback height; V5 = head length;V6 = neck length; V7 = back-loin length; $V 8=$ croup length $; \mathrm{V} 9=$ shoulder bone length; $V 10=$ body length; $V 11=$ head width; $V 12=$ chest width; $V 13=$ hip width; $V 14=$ thorax perimeter; $V 15=$ shin bone perimeter

No resultado da análise multivariada, observase que os animais de dois e três anos (idade de registro) foram agrupados juntos, diferenciando-se das outras idades, entre quatro a nove anos. $\mathrm{Na}$ segunda análise, observou-se que os animais apresentam medidas lineares crescentes, de forma proporcional com a idade.

Com o estudo de agrupamento determinaram-se as sub-regiões em relação às quinze medidas lineares. A região de Corumbá foi agrupada separada das outras regiões, concordando com a análise de variância. O agrupamento de sub-regiões, quando as partes diferentes do corpo foram avaliadas, mostrou bastante variação. As sub-regiões de Corumbá, Rio Verde, Rosário, Campo Grande, Barão do Melgaço, Araputanga e Diamantino, separaram-se em um grupo, enquanto ao formato de cabeça, ou seja, nestas regiões a cabeça do cavalo é diferenciada das cabeças dos cavalos das outras sub-regiões. Quando se agrupou a sub-região de acordo com a parte posterior do corpo do animal, houve maior número de grupos diferentes formados (6). Existe acentuada heterogeneidade no Pantanal Matogrossense interna que permite distinguir dez panta- nais (Adámoli, 1982), com características próprias, ecológicas e floristicamente diferenciáveis: Cáceres, Poconé, Barão de Melgaço, Paiaguás, Nhecolândia, Paraguai, Aquidauana, Miranda, Abobral e Nabileque (Mazza et al., 1994). Em geral, os agrupamentos feitos foram de acordo com a distribuição dessas sub-regiões, indicando possíveis diferenças entre os animais criadas nas diferentes regiões que precisam ser mais bem esclarecidas.

Os agrupamentos por ano de registro usando as medidas de altura, de comprimento e de largura do cavalo Pantaneiro, mostraram mensurações com maior variabilidade nos anos entre 1968 e 1974, enquanto que os animais nascidos entre 1963 e 1967 e depois de 1974 foram, em geral, com menor variação. Isto sugere que, principalmente em anos mais recentes, existe uma diminuição na variabilidade do cavalo Pantaneiro, talvez por causa de restrições colocadas na hora do registro ou pela própria escolha dos animais a serem registrados pelo criador. Os dados seguiram o mesmo tipo de agrupamento quando foram feitos agrupamentos com partes do corpo do animal (cabeça, parte central do corpo, a parte de frente e parte posterior). 


\section{Conclusões}

Os cavalos Pantaneiros são animais de estatura pequena, cujas medidas foram influenciadas pelo sexo, sub-região, idade de registro, ano do registro. Os animais da região de Corumbá apresentaram estatura mais elevada do que a média de todas as subregiões. Provavelmente isto pode ter ocorrido devido à estatura dos cavalos de origem, à presença de condições ambientais mais apropriadas e preferência por tipo de animal pelos criadores da região.

A melhor época para avaliar as medidas morfométricas dos animais seria a partir dos 4 anos de idade, pois, de acordo com a análise de variância e de agrupamento, os animais entre 2 e 3 anos ainda estavam em fase de crescimento.

Existe dimorfismo sexual para as características avaliadas e as correlações entre altura de cernelha, altura do dorso e altura da garupa foram altas e positivas, mas com as outras medidas lineares, as correlações foram médias e baixas.

\section{Literatura Citada}

ADÁMOLI, J. O Pantanal e suas relações fito geográficas com os Cerrados. Discussão sobre o conceito de "Complexo do Pantanal". In: CONGRESSO NACIONAL DE BOTÂNICA, 32., 1981, Teresina. Anais... Teresina: Sociedade de Botânica do Brasil, 1982. p.109-119.

BARBOSA, C.G. Estudo morfométrico na raça Mangalarga Marchador - Uma abordagem multivariada. Belo Horizonte: Universidade Federal de Minas Gerais, 1993. 77p. Dissertação (Mestrado em Zootecnia) Universidade Federal de Minas Gerais, 1923.

BECK, S.L. Eqüinos - ração, manejo e equitação. 2.ed. São Paulo: Criadores, 1989. 703p.

COOPER, S.R.; TOPLIFF, D.R.; FREEMAN, D.W. et al., Effect of dietary cation-anion difference on growth and serum osteocalcin levels in weanling horses. Animal Science Research Report, p.182-188, 1999.

CORREA FILHO. O cavalo Pantaneiro. Revista Medicina Veterinária, v.8, n.3, p.395-412, 1973.

COSTA, M.D.; BERGAMANN, J.A.G.; PEREIRA,C.S. et al. Avaliação dos fatores genéticos e de ambiente que interferem nas medidas lineares dos pôneis da raça brasileiras. Revista Brasileira de Zootecnia, v.27, n.3, p.491-497, 1998.

CRUZ, C.D. Programa Genes. Manual do Usuário. Viçosa: Universidade Federal de Viçosa. 1997. 442p.

COTHRAN, E.G.; SANTOS, S.A.; MAZZA, M.C.M. et al. Genetics of the Pantaneiro horse of the Pantanal region of Brazil. Review of Genetics and Molecular Biology, v.21, n.3, p.343-349, 1998.

DOMInGuES, O. Contribuição e estudo do cavalo Pantaneiro. Rio de Janeiro: Nobel, 1957. 19p.
FAUSTO, S. Mangalarga e o cavalo de sela brasileiro. 2.ed. São Paulo: Criadores, 1979. p.33-100.

JAKUBEC, V.; SCHLOTE,W.; JELINEK, J. et al. Linear type trait analysis in the genetic resource of the Old Kladrub horse. Archiv fur Tierzucht., v.42, p.215-224, 1999.

JOLIFFE, I.T. Principal component analysis. New York: Springer-Verlag, 1986.

MAWDSLEY, A.; KELLY, E.P.; SMITH, F.H. et al. Linear assessment of the Thoroughbred horse: an approach to conformation evaluation. Equine Veterinary Journal, v.28, p.461-467, 1996.

MAZZA, M.C.M.; MAZZA, C.A.S.; SERENO, J.R.B. et al. Etnobiologia e conservação do bovino Pantaneiro. Brasília: EMBRAPA, 1994. 61p.

REED, K.R.; DUNN, N.K. Growth and development of the Arabian horse. In: EQUINE NUTRITION AND PHYSIOLOGY SYMPOSIUM, 5., 1977, São Paulo. Proceedings... São Paulo: Universidade de São Paulo, 1977. p.76-98.

RIBEIRO, D.B. O cavalo: raças, qualidades e defeitos. Rio de Janeiro: Globo Rural, 1988. 290p.

SANTOS , S.A.; SERENO, J.R.B.; MAZZA, M.C.M. Origin of the Pantaneiro horse in Brazil. Archivos Zootecnia, v.41, S1, p.371-381, 1992.

SANTOS, S.A. Avaliação e Conservação do Cavalo Pantaneiro no Pantanal Mato-Grossense, In: REUNIÃO ANUAL DA SOCIEDADE BRASILEIRA DE ZOOTECNIA, 30., 1993. Rio de Janeiro. Anais... Rio de Janeiro: Sociedade Brasileira de Zootecnia, 1993. p.287-308.

SANTOS, S.A.; SOUZA, G.S.; OLIVEIRA, M.R. et al. Using nonlinear models to describe height growth curves in Pantaneiro horses. Pesquisa Agropecuária Brasileira, v.34, n.7, p.1133-1138, 1999.

SAS INSTITUTE. SAS User's Guide. Cary: 1999. v.8, 295p.

SAVEBA, I. Influence of grading with Thoroughbreds upon growth ability of East Bulgarian riding horses. Bulgarian Journal of Agricultural Science, v.4, p.519-523, 1998.

VASSILEY, D.; SABEVA, I. Genetic parameters of conformation traits in the East Bulgarian horse. Macedonian Agricultural Review, v.43, p.41-44, 1996.

ZAMBORLINI, L.C.; BERGMANN, J.A.G.; PEREIRA, C.S. et al. Estudo genético-quantitativo de medidas lineares de equinos da raça mangalarga Marchador. I. estimativas de fatores de ambiente e parâmetros genéticos. Revista Brasileira Ciência Veterinária, v.3, p.33-37, 1996.
Recebido em: 28/09/00 Aceito em: 04/10/01 